Article

\title{
THE EFFECT OF PROPRIOCEPTIVE EXERCISES ON BALANCE IN SEDENTARY STUDENTS
}

\section{ABSTRACT}

The increasing prevalence of sedentism in South African is a cause for concern, as it has been linked to the development of many health conditions and balance disturbances. This study aimed to assess the effects of a nine session progressive proprioceptive exercise program on balance in sedentary students. This was a single-blinded, randomized control trial. Seventy-four first and second year Physiotherapy students were willing to participate, of whom 45 students were included. After the initial physical activity test students were randomly allocated into the control $(n=19)$ and intervention $(n=26)$ group. Each participant's balance was assessed pre and post-intervention using the Romberg's test on the Alfa Stabilometric Platform. The intervention group $(n=26)$ participated in a nine session exercise program. The control group $(n=19)$ received a lecture and pamphlet. Seventy-eight percent of the participants were sedentary. The intervention group's pre and post-intervention scores showed a significant difference in Romberg's eyes open $(p=0.042)$ and Romberg's eyes closed $(p=0.046)$ tests. There was also a significant difference between the control and intervention group post-intervention scores; Romberg's eyes open ( $p=0.025$ ), Romberg's eyes closed $(p=0.036)$. This study indicated that a nine session progressive proprioceptive exercise program is effective in improving balance in sedentary students.

\section{KEYWORDS: SEDENTARY BEHAVIOUR, PROPRIOCEPTIVE EXERCISES, STUDENTS, BALANCE, PHYSIOTHERAPY}

\section{INTRODUCTION}

Sedentary behaviour along with physical inactivity are known contributors to a number of health conditions such as obesity, hypertension, diabetes and cardiovascular disease (Ortega et al., 2013; van Zyl et al., 2012). However they are independent entities and physically active individuals meeting the recommended activity norms may still be at risk to health problems due to prolonged sedentary behaviour during the rest of the day (Owen et al., 2010).

Sedentary behaviour is defined as a

\section{Corresponding Author:}

Preshani Reddy

Physiotherapy Department

College of Health Sciences

University of KwaZulu Natal,

Westville Campus

Faculty of Health Science

Email: reddypr@ukzn.ac.za distinct class of behaviours, characterized by little physical movement and low energy expenditure ( $\leq 1.5$ METs) (Owen et al., 2010). The most prevalent sedentary leisure-time behaviours have been described as watching TV, playing computer games, time spent on motorized transport and hobbies (Biddle et al., 2011). According to previous studies sedentary behaviour is increasing in developing countries, including South Africa, due to the rapid growth in urbanization and technological advancements (Owen et al., 2010; Guthold et al., 2008; Nigg, 2003). In 2008, the prevalence of sedentary people in South Africa was $47.6 \%$ of the country's total population (Guthold et al., 2008). A recent systematic review among South African children and youth revealed that urbanization was associated with a developing trend towards increasing sedentary behaviours due to lower levels of physical activity higher levels of television watching and other levels of sedentary pursuits (Muthuri et al., 2014). A greater period of time spent in sedentary behaviour leads to more physical inactivity, which in turn has a negative impact on balance, and is therefore related to a greater risk of falls in this population (Gokdemiret al, 2012). In a study done by Gordon-Larsen et al (2004), it was found that sedentism, was associated with health problems, balance disturbances and a greater risk of falls which was carried from childhood into adulthood.

Balance can be defined statically as the ability to maintain a base of support with minimal movement; and dynamically as the ability to perform a task while maintaining a stable position (Gokdemir et al., 2012). Balance is found to be decreased in sedentary people due to reduced neural control of the trunk. This causes a lack of stability in 


\section{KTAAPE \\ KINESIOLOGY THERAPEUTIC TAPE \\ IS ON PROMOTION!}

\section{Reduced price per roll - R89}

\section{Buy 5 rolls get 1 FREE}

KT Tape Original Cotton 5m Rolls - Pre-cut and Uncut

Selected Colours: Beige, Camo, Grey, Light Blue, Navy, Orange, Pink, White and Yellow

Mix and Match any colour or variant in any combination - Promotion valid while stocks last

To place an order - simply send an email to sales@kttape.co.za

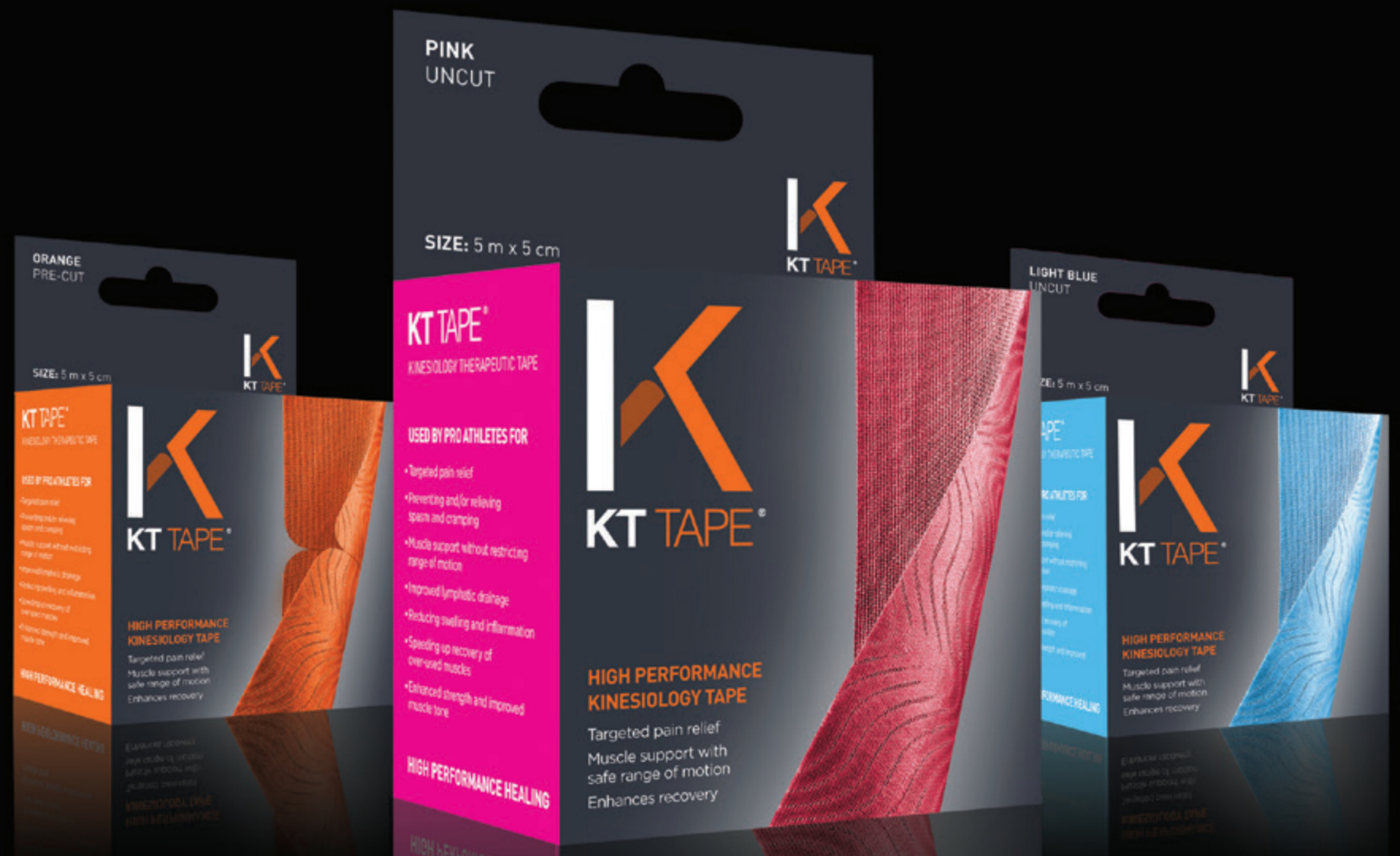

Pre-Cut Roll: Includes 20 perforated pre-cut strips for easy "I" and "Y" application requirements.

Uncut or Classic Roll: Continuous uncut roll providing the flexibility to cut to unique application requirements.

\section{HIGH PERFORMANCE HEALING}


Figure 1: Distribution of gender between Control and Intervention Groups

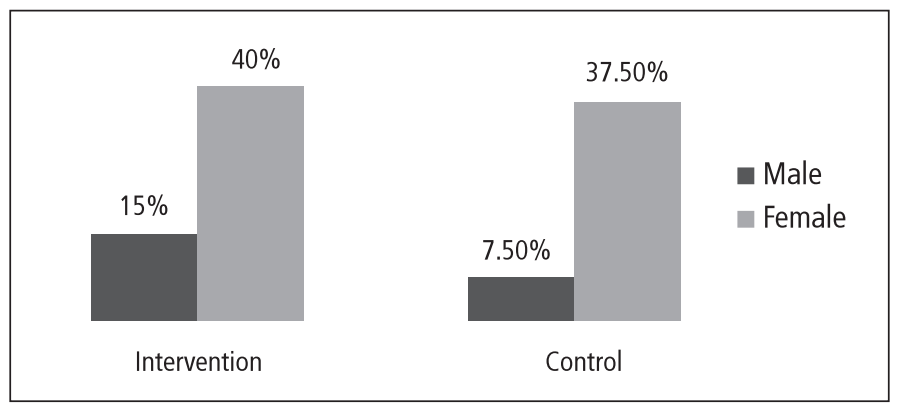

Figure 2: Distribution of Race between Control and Intervention Groups the trunk as a result of abnormal activation and co-ordination, reduced tone of the core muscles, and decreased proprioception or awareness of the pelvic position (Gokdemir et al., 2012). Stability of the lumbo-pelvic region is maintained dynamically utilizing the active components (muscles), passive components (joints and ligaments) and the control of these systems (central nervous system) (Hodges and Cholwicki, 2007; Panjabi, 2003, Punjabi, 1992).

Akuthota and Nadler (2004) describe the core as a muscular corset. It is boxshaped, with the abdominals in the front, the paraspinal and gluteal muscles at the back, the diaphragm at the top and the pelvic and hip girdle musculature at the bottom. During the co-activation and contraction of these core muscles, intraabdominal pressure is increased and maintained to achieve stabilization of the spine, therefore providing functional stability (Akuthota and Nadler, 2004). According to Samson (2005), the core is the foundation from which human movement originates. Functional stability is provided not only through the coactivation of the core muscles, but also through the fascial system found in the abdomen, which helps to avoid distorted patterns of movement. The co-activation of the core muscles contributes to retraining proprioception, and therefore balance (Samson, 2005).

The proprioceptive feedback system is responsible for the awareness of posture, movement and equilibrium changes in relation to the body (Samson, 2005). Afferent proprioception provides feedback to the central nervous system for the co-ordination and regulation of the kinetic chain. Impaired afferent proprioception results in a decreased awareness of the position of the body or body part in space. Impaired proprioception may therefore lead to pathologies relating to the musculoskeletal system, as well as habitual poor movement and abnormal neurodynamic sensation (Comerford and Mottram, 2001). Samson (2005) highlighted the importance of focusing on biomechanical postural alignment with slow and controlled movements, and the co-activation of the core musculature in accurately retraining proprioception, thereby improving balance.

There is a lack of literature on an intervention to improve balance specifically in a sedentary population. However, a review of literature concerning techniques used to improve balance in tennis athletes, the elderly, and people who have sustained previous ankle injuries, has shown proprioceptive exercises, incorporating core stability and strengthening, to be the most successful (Samson,2005; Gauchard et al., 2008; Blackburn et al., 2000) in comparison to the strength training of muscles, joints and tendons. Strength training showed to have a smaller improvement in balance than that of proprioceptive training (Heitkamp et al., 2001). The associated decreased balance found in people who have sustained previous ankle injuries resulted in this study using progressive proprioceptive exercises, incorporating core stability and strengthening, to improve their balance. Literature has shown good results with exercise programs ranging from 18 sessions (Blackburn et al., 2000) to a 5 week (Samson, 2005). Due to the timeconstraints of students, this study decided to utilize a nine session exercise intervention to determine if it was effective in improving balance of sedentary students. This study aimed to assess the effects of a nine session progressive proprioceptive exercise program on balance in sedentary students.

\section{METHODS}

The study was a single blinded, randomized control trial. The study population consisted of 102 first and second year Physiotherapy students at the University of KwaZulu-Natal, of whom $74(73 \%)$ volunteered to participate in the study, with $45(61 \%)$ of the 74 meeting the inclusion criteria of being sedentary. Balance was assessed in each participant using the Romberg's test (eyes open and eyes closed) on the Alfa Stabilometric platform. Each participant stood on the Alfa Stabilometric platform marked with a Cartesian plane to ensure identical foot placement. Changes in balance were captured on the platform machine by blinded researchers and were represented as the area of deviation from centre of pressure (COP) specific to each individual. Using the ballot method, 26 students were randomly allocated into the Intervention group and 19 into the Control group.

The Intervention group participated in a nine session progressive proprioceptive exercise program. Each session consisted of a five minute warm-up, followed by five minutes of general body stretches, there-after, 15 minutes of proprioceptive exercises were performed and the session ended with a five minute cool down. The progressive proprioceptive exercises were adapted from a study done by Samson in (2005), which incorporated core stabilization and strengthening. The program was conducted over a three week period, with three sessions per week, and the exercises were progressed to a greater difficulty at the beginning of each new week. Each exercise focussed on the correct biomechanical postural alignment. These exercises were performed in a slow and controlled manner, with verbal and visual stimulation ensuring the co-activation of the pelvic floor, transverses abdomin is, and multifidis muscle groups. To ensure that the exercises were done correctly and effectively, the researchers conducting the exercise sessions continually reminded participants to contract these 
muscle groups during each exercise.

The control group was given a formal lecture explaining the effects of sedentary behaviour, the importance of proprioceptive exercise and its positive effects on balance. They were provided with a pamphlet demonstrating the same proprioceptive exercises used in the intervention group. One week post completion of the intervention program, the balance of both the Intervention and Control groups were assessed in the same manner as the pre-intervention assessment.

\section{Data collection tools}

Demographic and Health questionnaires were given to the participants, firstly to obtain demographic data, and secondly, to ensure that they did not have any health conditions that could be compromised by their participation. The International Physical Activity Questionnaire (IPAQ) is a reliable and valid tool which was used to determine the sedentism of the participants (Craig et al., 2003). A basic general health questionnaire was also given to each participant in the intervention group prior to each session to ensure that they were healthy enough to participate in the class. The Romberg's test was used on the Alfa Stabilometric platform and was found be reliable, as it incorporates proprioception, the vestibular system and sight, which all contribute to balance (Beraquist et al., 2005).

\section{DATA ANALYSIS}

Data was captured by a blinded researcher on the Alfa Stabilometric platform apparatus using the Romberg's tests which accurately assesses balance of participants. The coded data was then collected and captured into Microsoft Excel by an independent researcher. The data was analysed by a qualified statistician using SPSS v.21. The analysis of variance (ANOVA) statistical test was used to analyse the differences between the groups. The statistical significance (p-value) was set at $\leq 0.05$.

\section{Ethical clearance and considerations}

A gatekeeper letter was obtained from the academic leader of the Physiotherapy Department and consent was given by the College of Health Science, both at the University of KwaZulu-Natal (UKZN). Ethical clearance was granted by the UKZN School of Health Sciences
Research Ethics Committee (SHSEC 023/13). Each student volunteer signed a consent form prior to participation, and was informed that they could withdraw at any time. Participant anonymity was maintained throughout the study. All procedures and equipment used were standardised and calibrated. To ensure the sound health of the participants, a general health screening process was done before each intervention session and a qualified first aider was present at these sessions. Data was collected, coded and stored either on a password protected personal computer or in a secure cabinet.

\section{RESULTS}

Five participants withdrew during the intervention phase of the study, reducing the sample size of the group to 40 participants. They withdrew due to difficulties regarding time constraints, and were unable to attend all sessions throughout the period of this study. The attrition rate was found to be $11 \%$, and had no significant impact on the results in this study, as the raw data collected was specific to each individual who participated. As depicted by Table 1, no significant difference was found between the pre-intervention test scores of the participants who withdrew and those who completed the study.

Of this study's sample group ( $\mathrm{N}=40)$, $77.5 \%(\mathrm{n}=31)$ were female and $22.5 \%$ $(n=9)$ were male. As depicted by Figure 1, the men accounted for $7.5 \%$ $(n=3)$ in the control group and $15 \% \quad(n=6)$ in the intervention group, and the women accounted for $37.5 \%(n=15)$ in the control and $40 \%(n=16)$ in the intervention group. The distribution of race within the study was $45 \%(n=18)$ African, $35 \% \quad(n=14)$ Indian, $\quad 12.5 \% \quad(n=5)$ White and 7.5\% (n=3) Coloured (Figure 2).

There was no significant difference between the control group's pre and post-intervention scores of the Romberg's eyes open test $(p=0.369)$ and Romberg's eyes closed test $(\mathrm{p}=0.671)$, as shown in Table 2. However, a significant difference was found in the intervention group's pre and postintervention scores of the Romberg's eyes open test $(\mathrm{p}=0.042)$ and Romberg's eyes closed test $(p=0.046)$ (Table 2$)$. In addition, the results show a significant difference between the control and intervention groups' post-intervention scores (Table 3) of Romberg's eyes open $(\mathrm{p}=0.025)$ and Romberg's eyes closed $(\mathrm{p}=0.036)$, which implies a greater balance improvement was found in participants in the intervention group.

\section{DISCUSSION}

Life has become more demanding,with little time being left to accommodate regular leisure and exercise activities (Mckee et al., 2005). A study done on adolescents in 2012 , found $35 \%(n=14)$ of a sample population of 40 to be sedentary, while in this study, prior to the implementation if the inclusion criteria $58(78 \%)$ of the 74 students, almost double that of the aforementioned study, were found to be sedentary. This indicates a need for an intervention in reducing sedentism in the young-adult age group.

As more South African youth begin to exhibit sedentary behaviours, one can anticipate a decline in health (Muthuri et al., 2014; Ortega et al., 2013; van Zyl et al., 2012; Gutholdet al., 2008). These health complications initiate a ripple effect in decreasing work productivity, which in turn leads to a disruption in the

\section{Table 1: Difference between Pre-test scores of Participants that withdrew and Participants that remained.}

\begin{tabular}{|l|l|}
\hline Romberg's Tests & Significance \\
\hline Eyes open & $\mathrm{p}=0.943$ \\
\hline Eyes closed & $\mathrm{p}=0.255$ \\
\hline
\end{tabular}

Table 2: Differences between Pre and Post Test scores

\begin{tabular}{|l|l|l|}
\hline $\begin{array}{l}\text { Romberg's } \\
\text { Tests }\end{array}$ & $\begin{array}{l}\text { Control } \\
\text { Group }\end{array}$ & $\begin{array}{l}\text { Intervention } \\
\text { Group }\end{array}$ \\
\hline Eyes Open & 0.369 & 0.042 \\
\hline Eyes Closed & 0.671 & 0.046 \\
\hline
\end{tabular}

Table 3: Difference between the Control and Intervention Post-Intervention scores

\begin{tabular}{|l|l|}
\hline Romberg's Tests & Significance \\
\hline Eyes open & $\mathrm{p}=0.025$ \\
\hline Eyes closed & $\mathrm{p}=0.036$ \\
\hline
\end{tabular}




\section{AccountsdotCom offers!}

- charging to be hand collected, e-mailed or faxed

- billing and submitting via QEDI

- sending statements to patients via post, fax or e-mail

- sending weekly sms messages for member liable accounts

- taking legal steps for bad debt, without extra costs

- reconciliation with medical aid on accounts from 60 days

- full reconciliation report

- banking of cheques for the practise

- printing of all month-end documents

- printing of locum reports for easy payments

- hand delivering of all IOD / Polmed IOD accounts

- handling of al public enquiries

- reconciliation of medical payments with practitioners bank statements

- handling of all extra requests

\section{All of this for a set fee!}

If you're looking for extra special service where the practitioner as well as the patient's needs are handled with the utmost care ... AccountsdotCom is the solution!

Phone now 012 653-7200 or 012 653-7122 or fax $012653-7850$ or e-mail accountsdotcom@gmail.com

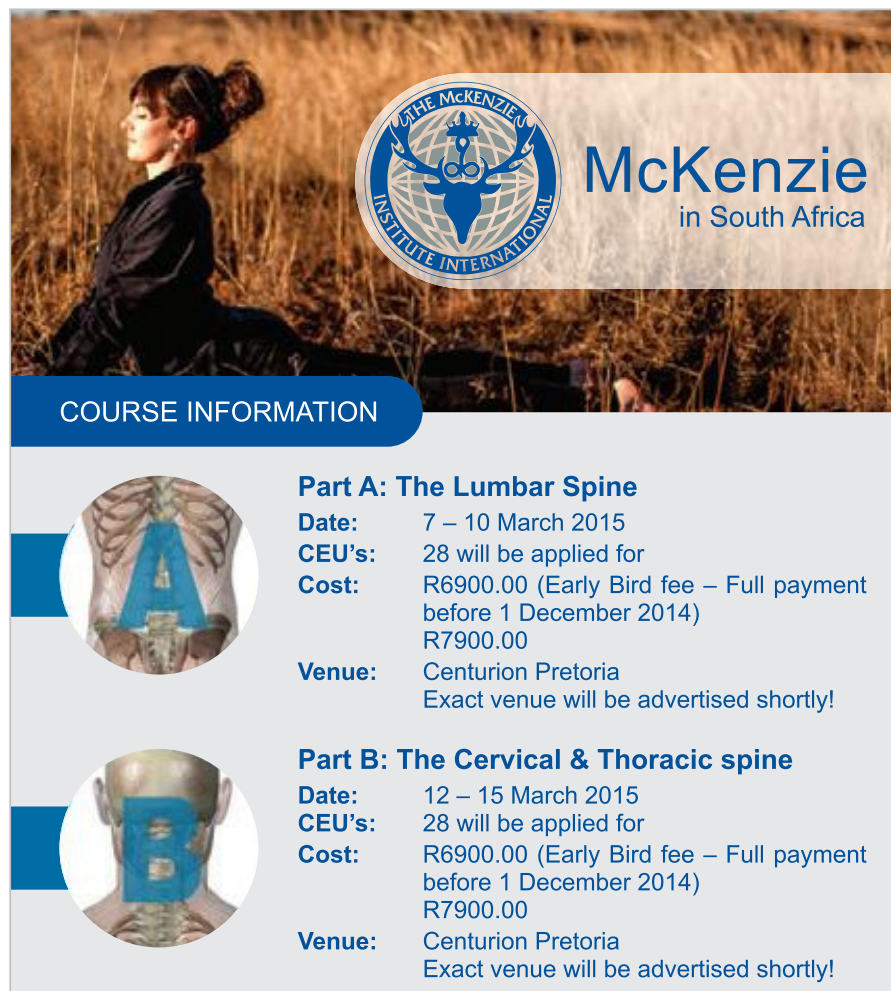

ABOUT THE PRESENTER

GRANT WATSON Dip Phys, Dip MT, ADP(OMT), Dip MDT, MCSP Deputy Director of Education for the McKenzie Institute International, co-author of "Treat Your Own Knee", "Treat Your Own Shoulder" and "Treat Your Own Strains, Sprains and Bruises".

Contact: (012) 6646128 | iangrey@physiorooms.co.za www.facebook.com/McKenzieSA country's economy. It was also found that these health conditions decrease a country's average age of mortality (Adler and Newman, 2002). This indicates the possibility of using this exercise program for those with time constraints to improve their balance and reap the benefits of an active lifestyle, as well as to combat the health conditions that stem from sedentary behaviour such as poor balance.

This study is similar to others done by Gauchard et al (2008), Samson (2005) and Blackburn et al (2000)which also found proprioceptive exercises to be effective in improving balance. Gauchard et al (2008) found that the regular practice of proprioceptive physical activity improves balance in the elderly, whereas Samson (2005) showed that a five week proprioceptive exercise program, incorporating core stabilization and strengthening, improves balance in tennis athletes. Blackburn et al (2004) found an 18 session proprioceptive exercise program to be effective in improving balance in patients that had previously sustained ankle injuries. The same five week progressive proprioceptive exercise program done by Samson (2005) was used in this study, but was condensed into a three week, nine session progressive proprioceptive exercise program. The balance reassessment was done one week post-intervention as per Samson (2005), which indicates that the effects of this program could be sustained. Proprioception in the lumbo-pelvic region is necessary to provide an accurate anticipatory response of the regions musculature during both static and dynamic situations (Hodges and Cholewicki, 2007; Panjabi, 1992). Furthermore concurrent training of the global trunk muscles as well as the deeper stabilizer muscles assists functional integration more efficiently than training them independently (Commerford and Mottram, 2001).The effectiveness of the condensed program demonstrated in this study shows that balance improvements can be achieved in nine sessions over a short period of three weeks.

This study improved balance in the young-adult age group of sedentary students; which addresses one of the effects of sedentism and will assist in reducing falls at a younger age. As inactivity is usually carried from childhood into adulthood (Gordon-Larsen, Nelson and Popkin, 2004), the exercise program used in this study may improve balance thus preventing the high risk of falls associated with poor balance being carried forward into later life.

\section{CONCLUSION}

This study highlights a high prevalence of sedentismin the first and second year Physiotherapy students at UKZN. It also highlights a significant improvement in balance in sedentary students following a nine session progressive proprioceptive exercise program.

\section{Limitations and recommendations}

Limitations were experienced regarding the students' free time for the intervention sessions, which lead to the withdrawal of some students from the study. Due to time constraints, the sample size was limited to 1 st and 2 nd year physiotherapy students.

This study can be repeated with different age groups to determine whether the level of balance improvement is agerelated. Longitudinal studies also need to be done to determine the long-term effects of this program on balance. 


\section{REFERENCES}

Craig CL, Marshall AL, SjoStrom M, Bauman AE, Booth ML,Ainsworth BE, Pratt M, Ekelund U, Yngve A,Sallis JF, Oja P2003 International Physical Activity Questionnaire: 12-Country Reliability and Validity. Medicine \& Science in Sports \& Exercise35(8):1381-1395

Adler NE, Newman K 2002 Socioeconomic disparities in health: Pathways and Polices. Health Affairs 21(2):60-76.

Akuthota V, Nadler S 2004 Core Strengthening. American Academy of physical medicine and rehabilitation 85 (3 Suppl 1):s86-s92.

Biddle SJH, Cameron N, Gorely T, Marshall SJ 2009The prevalence of sedentary behavior and physical activity in leisure time: A study of Scottish adolescents using ecological momentary assessment. Preventive Medicine 48(2):151-155.

Blackburn T, Guskiewicz KM, Petschauer MA, Prentice, WE 2000 Balance and Joint Stability: The Relative Contributions of Proprioception and Muscular Strength. Journal OfSport Rehabilitation, 9(4): 315-328

Brug J, Chinapawa M, Mechelen W, Proper K, Singh A 2011 Relationship between young peoples' sedentary behavior and biomedical health indicators: a systemic review of proprioceptive studies. Obesity Reviews 12: e621-e632.

Guthold R, Ono T, Strong K,Chatterji S, Morabia A2008 Worldwide Variability of Physical Inactivity, A 51-Country Survey.American Journal Preventative Medicine; 34(6):486-494

Comerford MJ, Mottram SL 2001 Movement and stability dysfunction-contemporary developments. Manual Therapy (2001)6(1): 15-26.

Gauchard GC, Gangloff P, Jeandel C, Perrin PP 2003 Influence of Regular Proprioceptive and Bioenergetic Physical Activities on Balance Control in Elderly Women.Journal of Gerontology: Medical Sciences 2003; 58A (9): 846-850

GokdemirK, Cierci AE, Er F, Suveren C, Sever O 2012 The Comparison of Dynamic and Static Balance Performance of Sedentary and Different Branches Athletes. World Applied Sciences Journal 17 (9): 10791082

Heitkamp HC, Horstmann T, Mayer F, Weller J, Dickhurt HH 2001 Gain in Strength and Muscular Balance After Balance Training. International Journal of Sports Medicine 22 (4): 285-290

Hodges PW, Cholewicki J 2007 Functional control of the spine. In: Vleeming A, Mooney V, Stoeckart R, Wilson P (eds.), Movement, Stability \& Lumbopelvic Pain, 2nd edn, pp489-512. Edinburgh: Churchill Livingstone.

Mckee M, Mortensen J, Sauto Arce R, Suhrcke M 2005 The contribution of health to the economy in the European Union. The European Commission: 1-136

Muthuri S, Wachira L, Leblanc A, Francis C, Sampson M, Onywera V, Tremblay M 2014 Temporal trends and correlates of physical activity, sedentary behaviour, and physical fitness among school-aged children in Sub-Saharan Africa: a systematic review. International Journal Of Environmental Research And Public Health, 11(3), 3327-3359. doi:10.3390/ijerph110303327

Nigg CR 2003 Technology's influence on physical activity and exercise science: the present and the future.
Psychology of sports and exercises, 4(1): 57-65

Ortega, FB, Konstabel K, Pasquali E, Ruiz JR, Hurtig-Wennlöf A, Mäestu J, Lof M, Harro J, Bellocco R, Labayen I, Veidebaum T, Sjöström M 2013 Objectively measured physical activity and sedentary time during childhood, adolescence and young adulthood: A cohort study. Plos ONE, 8(4): 1-8. doi:10.1371/journal.pone.0060871

Owen N, Healy G, Matthews C, Dunstan D 2010 Too much sitting: the population health science of sedentary behavior. Exercise and Sport Sciences Reviews, 38(3): 105-113. doi:10.1097/JES.0b013e3181e373a2

Panjabi MM 2003 Clinical spinal instability and low back pain. Journal of Electromyography and Kinesiology, 13(4): 371-379. doi: http://dx.doi. org/10.1016/S1050- 6411(03)00044-0

Panjabi MM1992 the stabilizing system of the spine. Part I. Function, dysfunction, adaptation, and enhancement. Journal of Spinal Disorders 5(4): 383-389

Samson KM 2005 the effects of a 5-week core stabilization-training program on dynamic balance in tennis athletes. Unpublished Master's thesis, West Virginia University

Stillman BC 2002 Making sense of proprioception: the meaning of proprioception, kinaesthesia and related terms. Physiotherapy, 88(11): 667-676

van Zyl S, van der Merwe LJ, Walsh CM, Groenewald AJ, van Rooyen FC 2012 Risk-factor profiles for chronic diseases of lifestyle and metabolic syndrome in an urban and rural setting in South Africa. African Journal of Primary Health Care \& Family Medicine, 4(1): 1-10. doi:10.4102/phcfm.v4i1.346

\section{ERGONOMICS: MAKE YOUR TREATMENT LAST}

ERGONOMIC ANSWERS FOR PHYSIOTHERAPISTS

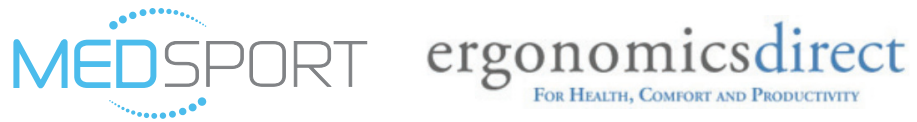

\section{IDESK LAPTOP STAND}

Transform a laptop into a desktop, improving posture \& reducing strain

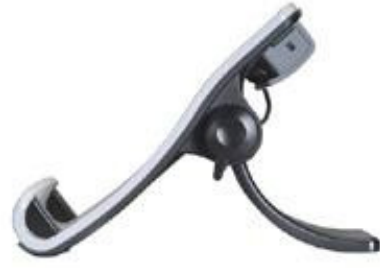

PRACTITIONER PRICE R399

SUGGESTED RETAIL PRICE R499

\section{SOHO BACK SUPPORT}

Dynamic back support - facilitates good posture - NAPPI coded

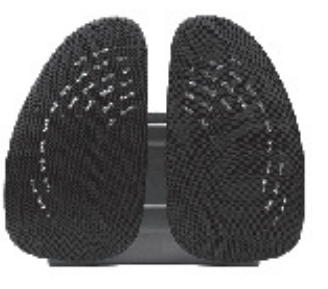

PRACTITIONER PRICE R549
136 bree street, cape town, 8001 tel: 0214262378 email: sales@medsport.co.za www.ergonomicsdirect.co.za www.medsport.co.za

\section{ADJUSTABLE FOOTREST}

Increases comfort \& decreases fatigue by ensuring even weight distribution

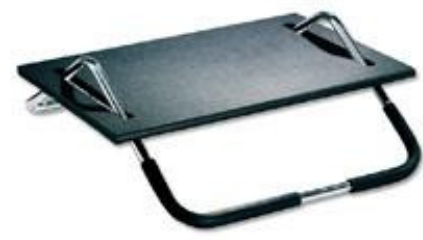

PRACTITIONER PRICE SUGGESTED R499 RETAIL PRICE R599

\section{REDUCED PRICING ON LARGER ORDERS}

LET YOUR WAITING ROOM WORK FOR YOU. CONTACT US TO BECOME A RESELLER 